\title{
On the Relationship between Learning Style and the Use of Pictures in Comprehension of Idioms among Iranian EFL Learners
}

\author{
Fatemeh Ghanavati Nasab \\ Department of English, Faculty of Foreign Languages, University of Isfahan, Iran \\ Akbar Hesabi \\ Department of English, Faculty of Foreign Languages, University of Isfahan, Iran
}

\begin{abstract}
The use of pictures in modern textbooks, multi-media programs and CALL packages seems to be an ever increasing phenomenon. As the individual learners differ in the way they pick up new material, this study aimed to investigate the relationship between the learning styles of the learners on the one hand and the use of pictures in comprehension of idiomatic expressions on the other among Iranian EFL learners. To this end, a total number of 39 B.A University students in two intact classes, majoring in English translation and English literature, received different instructions on a number of opaque idioms. Both groups were provided with definitions and examples for idioms; however, the picture group also took advantage of pictures for the target idioms. The findings revealed that a positive correlation existed between the participants' learning styles and their comprehension of idioms in the picture group.
\end{abstract}

Index Terms - opaque idioms, learning styles, EFL learners

\section{INTRODUCTION}

Formulaic language and pre-fabricated patterns have multiple names such as: collocations, popular sayings, phrases, greetings, idioms and proverbs. It is assumed that formulaic language bridges the gap between grammar and vocabulary. Pre-fabricated chunks appear in clauses like 'How's everything going?' which is an entity learned by language learners as a whole without paying further attention to its structure (Nattinger \& DeCarrio, 1992). As Weinert (1995) observed in several studies, memory treats multi-words (How's it going?) or multi-form strings (can't) as entities that resemble single words. In this sense, the meaning resembles to that of single words. For example, the simile 'as happy as a clam' can be substituted by a single word. Knowledge of formulaic language contributes to idiomaticity of language which is essential for having native-like proficiency and comprehension. Lack of knowledge about which words collocate with one another (like: ladies and gentleman, friend or foe, needle and thread) does not impede understanding. However, lack of knowledge about expressions like kick the bucket, a duck soup, a cool cucumber, etc. impedes comprehension. The same is true for expressions like ' I don't think so', 'I'm afraid not', 'never mind'. Therefore, it can be claimed that regardless of the learners' proficiency level, all learners can take advantage of pre-fabricated chunks for the facilitation of comprehension and learning (Nattinger \& DeCarricco, 1992).

Learners' fluency and successful communication is much in debt to collocational knowledge to the extent that positive relations are claimed to exist between this kind of knowledge and proficiency level of the students. The role of collocations in SLA has been widely acknowledged today. Pawly and Syder (1983) point to collocational knowledge as an indispensible element for having fluency. Lewis (2000) also points to the difficulty learners face to acquire sufficiently large vocabulary which contains pre-fabricated chunks of different types called collocations. Moreover, he believes in the priority being given to teaching collocations in every language course. A considerable part of this collocational knowledge consists of idioms.

The learning of new words as a sure sign of all living languages is a never-lasting, continuous process discernible both in first and second language. However, learning the genius of languages is deemed pointless without learning idioms. Demoting the significance of idioms leads to a bookish, stilted language with an unimaginative tone (Cooper, 1999). For some EFL learners, learning idioms is just a child's play while others find it 'swimming against the tide' and therefore struggle hard to learn and comprehend these gems of culture, imageability and creativity. Furthermore, while the application of idioms by native speakers creates a feel of innovative understanding, EFL students often find them problematic and thus in many ways idioms are not just a 'piece of cake' for them.

An idiom is roughly defined as a conventional multi-word unit which is structurally fixed and semantically opaque. There are a few ways to recognize multi-word expressions as figurative language; first, is the possibility for being reinterpreted for the intended meaning. In other words, something like a mental picture enables us to make sense out of non sense for the realization of figurative language. Second, knowledge of the fact that figurative language may be 
compositional (they smiled sheepishly), non-compositional (He's been shooting the breeze) or partly compositional (He had a long face when the game was rained off). While figurative language can be undone for the intended meaning, an idiom cannot be unpicked to work out the target meaning. Idioms therefore, refer to fixed multi-word units whose meaning cannot be understood from the sum of their parts (Mantyla, 2004).

\section{REASONS FOR THE INCLUSION OF IDIOMS IN INSTRUCTIONAL PROGRAMS}

Reasons for the inclusion of these chunks in instructional programs are abundant in second language acquisition field; some of which are pointed below.

Levorato (1993) points to the intriguing nature of idioms to engage imagination which finally facilitates the transformation of abstract meanings in to more concrete ones. According to Ferdinando (1996) and Moon (1998), idioms are highly useful in performing informative and evaluative functions which is related to the learner's imagination.

Idioms develop socio-linguistic and pragmatic competence and therefore enhance learner's communicative competence and increase learner's confidence in the appropriate use of language with native-like characteristics.

Yori (1989) relates learner's mastery of idioms to second language proficiency level. Research has shown that there is a contribution between storage of suitable multiword units in a learner's repertoire to their native-like selection and proficiency. In support of the mentioned claims Cowie (1992) claims that it's impossible to perform at an acceptable level, unless a mastery of an appropriate range of multi-word units has been assessed.

Understanding the processes involved in the first language acquisition of idioms can provide insights for learning them in a second language. With regard to teaching idioms in first language five main models has been proposed, preparing the grounds for further research and analysis (Glucksberg, 1993).

a) The idiom list hypothesis

b) The lexical representation hypothesis

c) The direct access hypothesis

d) The compositional hypothesis

e) The dual representation model

Some of these models view idiomatic meaning as haphazard and arbitrary, while others believe in the historical roots and the potentiality for pragmatic interpretation. Among the five models proposed, "the dual representation model" is regarded as the comprehensive framework for idiom processing by building on notions provided in previous models and adding linguistic processing as well as memory retrieval as necessary elements for the comprehension of idioms (Glucksberg, 1993).

\section{LEARNING STYLES}

Learning styles can broadly be defined as the learners' consistent ways of employing certain stimuli in pedagogical contexts. From another view, learning styles are closely connected with educational conditions under which learners are most likely to learn (Keefe, 1979). In yet another view, learning styles are viewed as the correspondence between the learners' fit and comfort and different methods of instruction (Renzulli \& Smith, 1978).

Although the notion of learning styles is widely accepted, no agreement is reached over the best way to measure the trend (Coffield et al. 2004). Some notes of caution must be mentioned in that learning styles just allocate learners along a continuum with some hints to discover the various forms of mental representations.

The shifting sands in the history of learning styles encompass a large number of models and theories with an attempt to take individual differences in pedagogical contexts in to account.

Kolb (1984) explains learning styles in terms of the process of the transformation of experience for the creation of knowledge. As he points out, knowledge is the outcome of the grasped experience which is then transformed by a complex mental process. Kolb (1984) further indicates active experimentation and reflective observation as two main components through which perceived information converts to knowledge. Kolb (1984) sets out a learning theory grounded on a four-stage cycle of learning. In this regard, his model offered an advantage over previous ones in that it represented both a way to perceive individual styles which he termed "learning styles inventory" and also a description of a cycle called "experiential learning" which is applicable to all learners. He considers four main types of learning at the core; (a) the concrete experience and the typical question "what is it?", (b) reflective observation based on the question "what does it mean?" , (c) abstract conceptualization with "what follows on?" and (d) active experimentation with "what...if...?". As he asserts despite individual differences, effective learning is the outcome of utilizing the four. In an attempt to formulate a learning style, style differences were investigated among engineering students to gain insights for the most efficient way to fulfill the learning requirements of all the students. To this aim, students were divided into sensing/intuitive, visual/verbal, active/reflective and sequential/ global. The findings alluded to the existing overlaps with previous models as each and every part was analogous to at least one dimension already proposed (Kolb, 1984).

In mid seventies, neuro-linguistic programming made an attempt to devise an instrument to make a true estimation of one's learning styles. The model took an interest in psychology, language and computer programming having high hopes for helping people to program their brains. As the NLP claims, the primary representational system (PRS) is what 
allows individuals to think in one of the four specific modalities; visual, kinesthetic, auditory and olfactory. Creativity was regarded as the individual's ability to replicate the modified version of other peoples' strategies with his own design. In this sense, NLP acts as a creative tool to help learners invent new things. As thus, NLP was defined as the magic that allows individuals to perceive how verbal and non-verbal communication applies to the human brain and therefore has its share to gain control over the presumed automatic functions of one's neurology (cited in Šabatová).

The typology put forward is the visual, auditory and kinesthetic type which is still the most celebrated model nowadays. As Ormod (2008) argues, while some learners benefit best from information presented through words (verbal learners), others learn best when it is introduced through pictures (visual learners). However, we should keep in mind that while learners take advantage of all the three modalities, the dominance of one or two is evident in filtering new information to be learned. In other words, the dominant style is what accounts for the best way to learn new information by adjusting the material to be learned (Messick, 1994).

- Visual learners are differentiated from others in terms of their tendency to describe their surrounding world through their own eyes. They learn best through visual aids such as diagrams, charts, graphs, maps and pictures. These learners mainly process information with their eyes.

- Auditory learners have a tendency to obtain information mainly through their ears benefiting most from sounds, music, teaching and discussion. These learners apt to record lectures, listen to oral presentations and appreciate taperecorded books.

- Kinesthetic learners or tactile learn best through actually doing things; moving, touching and acting out. These learners are fed up with sitting for long hours in class but enjoy performing tasks, exploring and conducting experiments.

Various studies have documented proof on the existing relationship between the learners' academic achievement and their preferred styles of learning. Nevertheless, little attention has been paid to the role of the learners' learning styles in the process of comprehension and acquisition of new idioms. Boers et al. (2009) conducted a study to examine the relationship between learning style variables and the effectiveness of pictorial elucidation as a mnemonic aid. To this end, thirty eight students aged 19 to 21 with varying proficiency levels were introduced to 100 new idioms. Then, the participants went through a multiple choice test, a gap-fill exercise and a learning style questionnaire. The questionnaire was answered by only 14 students. The results indicated a negative relationship between the students' styles and their recollection of idioms which were introduced by pictorial elucidation. Their study although highly significant, had some shortcomings. Firstly, the participants were not homogenized. Secondly, as Boers et al. (2009) acknowledge the small number of the participants makes it necessary for the findings to be replicated before any firm conclusions could be drawn. It is therefore the aim of the present study to shed more light on the issue by eradicating the limitations of their study.

\section{SIGNIFICANCE OF THE STUDY AND RESEARCH QUESTIONS}

The general findings among the investigation of facilitative techniques for learning and recall, suggest mnemonics as beneficial for the storage of knowledge in memory for further retrieval. Mnemonics are defined as a group of memory aids that facilitate the easy and quick assimilation and retention of information of all kinds. Mnemonics are what involve imagination in conjunction with all other individual senses, to reconstruct a dull, dry piece of information in to a vibrant memory (Oxford, 1990).

Mnemonic devices can be brought to notice in EFL settings for instructional purposes (White, 2011). Educators have long acknowledged the benefits of presenting information in multiple ways with the mantra " don't just say it; show it" (Nelson, Reed \& Walling, 1976). In this regard, it seems essential that teachers and practitioners in the field be aware of the potential benefits of such techniques and identify the most effective ones to apply in pedagogical contexts. Anyhow the way that individual learners sense, interact with and react to the learning environment is believed to be related to their learning styles which are the composite of their affective, cognitive and physiological factors (Keefe, 1979).

It is believed that identifying learners' styles has its share to alter the uncomforting, boring, and discouraging atmosphere in the class and can lend a hand to the instructor to adopt an approach that satisfies the learning requirements of more students. Many students are deemed to gain knowledge through the teacher's style which offers advantages only to those students whose style matches that of the teacher.

However, studies carried out in the context of Iranian EFL learners have mainly focused on idiom comprehension with no touch on individuals' learning styles. Therefore, the present study has utilized a learning style questionnaire to explore the probable relationship between the individuals' styles and their performance on idiom comprehension tests.

To this aim, the following research question was formulated.

Is there any significant relationship between the participants' learning styles and their performance on idiom comprehension tests in picture and control groups?

\section{METHOD}

\section{A. Participants}

A total number of thirty nine junior EFL learners in two intact classes at the University of Isfahan participated in the study. The participants were all B.A university students majoring in English translation and English literature with 
Persian as their first language. The students were homogenized through an Oxford Placement Test (OPT) and were considered to be at an intermediate proficiency level. The picture group comprised of twenty one and the control group of eighteen students aged 19 to 23 .

The participants in the control and picture group received different treatments:

Group 1 (control group): received idioms accompanied by definition and examples.

Group 2 (picture group): received idioms accompanied by definition, examples and pictures.

\section{B. Target Idioms}

Forty three idiomatic expressions were selected from Oxford Dictionary of Idioms. In this study, the term idiom satisfies the following criteria: 1) it is a non-compositional string, 2) it is a structurally fixed unit and, 3) the meaning of the expression is not deducible from the meaning of its constituent parts.

\section{Instruments}

\section{Oxford Placement Test}

The Oxford Placement Test was administered to choose homogeneous groups for experimental and control groups. It consisted of sixty items with the time-limit of thirty minutes. The OPT test as a standardized test is a reliable and valid tool to gain a true understanding of the students' proficiency level.

\section{English idioms}

The main material presented to the participants was 43 English idioms selected from Oxford Dictionary of Idioms, from among which 30 idioms were selected and used in the comprehension test.

\section{Test on Idiom Comprehension}

The test comprised of thirty items to assess the learners' comprehension of idiomatic expressions. Each item consisted of four options one of which was the correct answer. The allocated time was thirty minutes.

4. A Learning Style Questionnaire

To identify the participants' learning styles, a style questionnaire was adopted from Boers' study (2009). The twenty items on the questionnaire used a four- point scale ranging from almost never to very often. The participants were informed that there was no right or wrong answer and that the information would be kept confidential.

\section{PROCEDURE}

This study made use of non-random purposive sampling. The participants in two intact classes (the picture and the control group) received instruction on forty three opaque idioms. For validity purposes, the same instructor (the researcher) carried out the instruction in both groups. The participants in both groups were provided with a definition and an example for each idiom; the picture group, however, took advantage of pictures illustrating the literal readings of idioms. The instruction was offered in three successive sessions, each session introducing an average of thirteen to fifteen idioms. Immediately after the instruction, a test was administered to assess the participants' scores on the comprehension of idioms. The collected data was then organized and submitted to statistical analysis.

\section{DATA ANALYSIS AND RESUltS}

Both descriptive and inferential statistics were used to analyze the data. To discover the possible relationship between the individuals' learning styles on the one hand and their performance on the comprehension test on the other, Pearson Product Moment correlation was employed. The raw data was fed to the computer and the correlation was run by the Statistical Package for Social Sciences (SPSS) 21 software for each group.

The amount of $\mathrm{P}$-value $(\mathrm{P}<0.05)$ indicated that a positive relationship existed between the aforementioned variables in the picture group (see Table 6.1).

TABLE 6.1

CORRELATION BETWEEN STUDENTS' STYLES AND STUDENTS' SCORES ON IDIOM ACQUISITION IN THE PICTURE GROUP

\begin{tabular}{llll}
\hline \hline & & Acquisition & Picture Group \\
\hline \multirow{2}{*}{ Acquisition } & Pearson Correlation & 1 & .520 \\
& Sig. (2-tailed) & & .016 \\
& $\mathrm{~N}$ & 21 & 21 \\
\hline \multirow{2}{*}{ Picture } & Pearson Correlation & .520 & 1 \\
Group & Sig. (2-tailed) & .016 & \\
& $\mathrm{~N}$ & 21 & 21 \\
\hline \hline
\end{tabular}


TABLE 6.2

CORRELATION BETWEEN STUDENTS' STYLES AND STUDENTS'

SCORES ON IDIOM ACQUISITION IN THE CONTROL GROUP

\begin{tabular}{llll}
\hline \hline & & Acquisition & Control Group \\
\hline \multirow{3}{*}{ Acquisition } & Pearson Correlation & 1 & .049 \\
& Sig. (2-tailed) & & .833 \\
& $\mathrm{~N}$ & 21 & 21 \\
\hline \multirow{2}{*}{ Control } & Pearson Correlation & .049 & 1 \\
Group & Sig. (2-tailed) & .833 & \\
& $\mathrm{~N}$ & 21 & 21 \\
\hline \hline
\end{tabular}

However, the amount of $\mathrm{P}$-value in the control group $(\mathrm{P}>0.05)$ signified no meaningful relationship between the variables under study (Table 6.2). Based on the results, it can be concluded that the use of pictures for the comprehension of new idioms is in congruence with Iranian EFL learners' learning styles.

\section{CONCLUSION AND PEDAGOGICAL IMPLICATIONS}

The findings of the present study revealed that a positive correlation existed between the participants' learning style and the use of pictures in comprehension of idioms. However, no relationship between the mentioned variables was found in the control group. Therefore, it can be concluded that Iranian EFL learners stand to gain from the use of pictures and illustrations in the process of idiom comprehension with respect to their learning styles.

The results of this study were not in line with Boers' (2009) study. He reported on the distracting effect of pictures on idiom comprehension and retention among Dutch speaking students of Brussels. It is worth mentioning that despite his findings, Boers acknowledged that it is unrealistic to wean the learners off the use of pictures in pedagogical contexts.

It should be kept in mind that, no style has priority over the other and individuals may utilize different learning styles in different situations for performing different tasks. However, realization and attention to learning styles can provide insights for teachers in adopting different instructional tools for pedagogical purposes and not to rely heavily on a single method of instruction. Therefore, awareness of such preferred trends in learning may finally lead to better outcomes (Schmeck, 1988). Awareness of learners' learning styles can lead to the formation of strategies. As Keefe (1979) claims learning strategies as conscious techniques can affect one's learning outcomes especially taking one's learning styles into account.

\section{LIMITATIONS OF THE STUDY}

A number of limitations need to be considered to assist better research in the future. Firstly, the participants were randomly selected from one university and all were majoring in English. Therefore, the generalizability of findings should be treated cautiously regarding the small number of the participants. Moreover, students' learning styles were taken into consideration on the basis of a questionnaire which may have rendered a self-report on the students' assumed styles of learning. Upcoming studies, can utilize more instruments like observations, dairy notes and interviews to add to the validity of the data.

\section{REFERENCES}

[1] Boers, F., Piquer Piriz, A. M., Stengers, H., \& Eyckmans, J. (2009). Does pictorial elucidation foster recollection of idioms? Language Teaching Research, 13(4), 367-382.

[2] Coffield, F., Moseley, D., Hall, E., \& Ecclestone, K. (2004). Learning styles and pedagogy in post-16 learning: A systematic and critical review. London: Learning \& Skills Research Centre (http://www.LSRC .ac.uk).

[3] Cooper, T. C. (1999). Processing of idioms by L2 learners of English. TESOL Quarterly, 33 (2), 233-262.

[4] Cowie, A.P. (1992). Multiword lexical units and communicative language teaching. In: Arnaud, P.J.L., BeÂjoint, H. (Eds.), Vocabulary and Applied Linguistics (pp. 1-12). Macmillan, Basingstoke.

[5] Fernando, C. (1996). Idioms and Idiomaticity. Oxford: Oxford University Press.

[6] Glucksberg, S. (1993). Idiom meanings and allusional content. In Cacciari, C. \& Tabossi, P., Idioms: processing, structure, and interpretation. Hillsdale, 3-26. NJ: Lawrence Erlbaum Associates, Inc.

[7] Keefe, J. W. (1979). Development of the NASSP learning style profile. In COGNITIVE STYLES 479J. W. Keefe (Ed.), Profiling and utilizing learning style (pp. 1-28). Reston, VA: National Association of Secondary School Principals.

[8] Kolb, D. A. (1984). Experiential learning: Experience as a source of learning and development. Englewood Cliffs, NJ: Prentice Hall.

[9] Levorato, M. C. (1993). The Acquisition of Idioms and the Development of Figurative Competence. In C. Cacciari and P. Tabossi (eds.), Idioms: Processing, Structure, and Interpretation. Hillsdale, NJ: Lawrence Erlbaum Associates, 101-128.

[10] Lewis, M. (2000). The Lexical Approach. Hove, UK: Language Teaching Publications.

[11] Mäntylä, K. (2004). Idioms and language users: the effect of the characteristics of idioms on their recognition and interpretation by native and non-native speakers of English [online]. University of Jyväskylä. (May 31, 2005) http://selene.lib.jyu.fi:8080/vaitos/studies/studhum/9513917177.pdf. 
[12] Messick, S. (1994). The nature of cognitive styles: Problems and promises in educational practices. Educational Psychologist, 19, 59-74.

[13] Moon, R.E. (1998). Fixed expressions and text: a study of the distribution and textual behaviour of fixed expressions in English. Oxford Studies in Lexicology and Lexicography. Clarendon Press, Oxford.

[14] Nattinger, J. R., \& DeCarrico, J. S. (1992). Lexical phrases and language teaching. Oxford: Oxford University Press.

[15] Nelson, D.L, Reed, V.S. and Walling, J.R. (1976). Picture superiority effect. Journal of Experimental Psychology: Human Learning and Memory, 2, 523-28.

[16] Ormrod, J.E. (2008). Educational psychology: Developing learners (6 $6^{\text {th }}$ ed.). Upper Saddle River, NJ: Pearson.

[17] Oxford idioms dictionary for learners of English. (2006). Oxford: Oxford University Press.

[18] Oxford, R.L. (1990). Language learning strategies: What every teacher should know. New York: Newbury Houst Publishers.

[19] Pawley, A., \& Syder, F. H. (1983). Two puzzles for linguistic theory: nativelike selection and nativelike fluency. In J. C. Richards \& R. W. Schmidt (Eds.), Language and Communication (pp. 191-225). New York: Longman.

[20] Renzulli, J.S., \& Smith, L.H. (1978). The learning styles inventory: A measure of student preference for instructional techniques. Mansfield Center, CT: Creative Learning Press.

[21] Šabatová, J. (2008). Learning styles in ELT. Brno, Theses and desertations.

[22] Schmeck, R. R. (Ed.). (1988). Strategies and styles of learning. New York: Plenum Press.

[23] Weinert, R. (1995). The role of formulaic language in second language acquisition: A review. Applied Linguistics 16 (2). 180 205.

[24] White, R. (2011). Imagery helps you learn a new language. http://www.memorise.org/brain-articles/imagery-helps-learn language- 001503.html.

[25] Yori, C.A. (1989). Idiomaticity as an indicator of second language proficiency. In K. Hyltenstam and L.K. Obler (Eds.), Bilingualism across the lifespan: Aspects of acquisition, maturity and loss. Cambridge: Cambridge University Press.

Fatemeh Ghanavati Nasab received her BA degree in English Literature from the University of Isfahan in 2010. She is currently an MA student in Teaching English as a Foreign Language (TEFL) at the University of Isfahan. Her areas of interest include second language acquisition, sociolinguistics and cognitive linguistics.

Akbar Hesabi is assistant professor of linguistics at University of Isfahan, Iran. He has supervised and advised several theses in applied linguistics and translation studies. His areas of interest include Technology in teaching and translation, neurolinguistics, cognitive linguistics. 